\title{
Tracing to the Source and Reconstruction: Physical Humanistic Education from the Perspective of First-Class University Construction
}

\author{
DANG Guangwei
}

Physical Education Department, Jilin Institute of Chemical Technology, Jilin, Jilin, China

Email:13614320680@139.com

\begin{abstract}
First-class universities must have first-class humanistic education. This paper traces the humanistic attribute of school physical education from the perspective of first-class university construction and reconstructs the ways of humanistic education of physical education. According to the research, sports spirit can nurture the spiritual core of talents, but we should insist on the organic combination of sports humanistic value and utilitarian value, follow the diversity of physical humanistic education goal orientation and keep the implicit nature of physical humanistic education mode. Sports spirit is the source of university spirit. Sports culture promotes the development of first-class university spirit. Physical education is a kind of sports endowed with culture, and physical education teachers should also have profound humanistic connotation of physical education.
\end{abstract}

Keywords: first-class university, physical education, humanistic education

\section{溯源与重构: 一流大学建设视角的体育人文教育 \\ 党广伟}

吉林化工学院体育教学部, 吉林, 吉林, 中国

Emai1:13614320680@139.com

\section{摘要}

一流大学必有一流的人文教育, 本文以一流大学建设为视角对学校体育的人文属性进行溯源, 并 对体育人文教育途径进行重构。经研究认为: 体育精神能够哺育人才的精神内核, 但应坚持体育的人 文价值与功利性价值有机结合, 遵循体育人文教育目标导向的多元性, 保留体育人文教育方式的内隐 性; 体育精神是大学精神的源泉, 以体育文化推动一流大学精神的发展; 体育是赋有文化的体育, 体 育教师也应具有厚重的体育人文内涵。

关键词: 一流大学; 体育; 人文教育

\section{1.引言}

建设世界一流大学和一流学科, 是党中央、国务院 作出的重大战略决策, 对于提升我国教育发展水平、增 强国家核心竞争力、奠定长远发展基础, 具有十分重要 的意义。[1]长期以来, 我国是一个教育大国而并非一个 教育强国, 国人获得诺贝尔奖的数量能够在一个侧面反 映出我国在培养一流人才方面与教育强国的差距。冷战 期间, 苏联先于美国成功发射第一颗人造卫星, 美国人 认为艺术教育的落后削弱了美国的科技创造力, 是艺术 哺育了苏联的科学家。我们也应该像美国人那样去反思, 重新审视我们的高等教育。建一流大学要培养一流人才, 一流人才的内在素养往往是靠看似无用的人文和艺术 教育来承担的。凡一流大学必拥有一流人文教育, 凡没
有一流人文教育的大学成不了一流大学。[2]建设一流大 学需要高度重视人文教育, 不然所谓创新性人才的培养 就无从谈起。

在大学教育体系当中，课程名称直接带有“育”字的 并不多, 体育是其中一个。学校体育作为教育的重要组 成部分, 体育的目的本应该与教育目的保持高度一致, 是要实现育人这一根本目的。但现实中的体育往往被 “体质改善论”、“运动技术中心论”以及“金牌主义”等功 利思想左右, 结果呢, 全国学生体质连续下降的趋势并 未得到明显改善, 大学生们对最基本运动技能的掌握也 并不理想。学校体育实践一直在“器物层”上不知疲备地 寻求着，效果却不尽人意。“体”是方法手段，“育”是目 的但不应仅停留在一般的“身心”层面, 体育应当是一个 人文过程, 更应该是关于价值的事情。

学校体育要破桎梏、寻发展, 需要重新审视体育的 
physical education 则指的是依据人之自然而然的生命力 量而进行的教育”。[5]日本将“physical education”译为 “身体之教育”是否造成了体育内涵的窄化, 仍有待商榷。 最先进入中国人视野的“体育”，是基于一种教育方 式出现在教育领域的。受日本“身体之教育”理念的影响, 又恰逢清末国人吸食鸦片、甲午战败这样的历史背景, 所以我国 19 世纪末从日本引进的 “体育”也是基于“身 体之教育”概念的。当时的体育就是身体培育、体质教 育或体能训练等身体层面的教育活动, 这个概念下的体 育在一定程度上缺失了人文内涵。

受“身体的教育”思想影响, 目前我国学校体育仍存 在“体质论”、“技能论”、“竞技论”等问题。从体育的现 实来看, 教学实践中存在“重体质轻精神”、“重体能轻 心理”、“重技术轻人文”等现象, 体育在一定程度上热 了“物”冷了“人”。如果我们的体育不是以学生的心灵和 本性作为出发点和归宿, 而是只专注于对“技术”和“体 质”的追求, 在培养人才的过程中将会遮蔽体育的人文 价值, 将使“育”变得失去意义和难以实现。

\section{3.学校体育教育的人文属性溯源}

亚里士多德曾讲“智慧在于研究最初的价值和本 原”, 要探索当代学校体育发展的去向, 就要理清体育 从哪里来、是什么样子这个原点问题。

\section{1 六艺中的“射”就已体现了人文教育价值}

“西周的“射”和“御”教育, 不但是我国学校体育的鼻 祖, 而且在世界范围内, 它也是有文字可查的最早的学 校体育。”[3]研究西周六艺中的“射”是一种怎样的体育 教育方式, 对我们今天审视体育的属性仍有指导意义。 礼记.射义记载“故射者, 进退周还必中礼, 内志正, 外 体直, 然后持弓矢审固; 持弓矢审固, 然后可以言中, 此可以观德行矣。” [4]周代的射不仅是作为战争和狩猎 手段在传授射箭技术, 更是讲求“射以观德”, 注重“德 成而上、艺成而下”。这就使习射逐渐成为一种教育载 体和形式, 通过习射达到“明君臣之礼”和“明长幼之序”。 因此, 最早的学校体育就已经超越了“技术”或“体能”范 畴, 通过习射来 “正心”、“笃志”“诸己”, 进而实现对德 的培育, 射礼又规范了行为与道德的合一, 是一种术道 并重、德艺双修的教育方式。

\section{2“体育”一词的引进在一定程度上缺失了人文教育 内涵}

我国“体育”一词是从日本引入的, 而日本是从英文 “physical education”翻译而来的, 日本曾将“physical education”翻译为“身体之教育”、“体之教”、“关于身体 的教育”等不同方式, 后来改进为“体育”。从文字的表 达我们不难看出日本当时的“体育”主要是对“身体的教 育”。牀杰曾在其博士论文中提到: “事实上,physical一 词的内涵极为宽泛, 其词根来源于古希腊语中的 physis, ‘指依靠自己的力量而成长的东西'......而

\section{3 从“身体的教育”到“通过身体的教育”是理论意义 上的回归}

“美国著名的体育界领袖托马斯·伍德 (Thomas Wood) 在 1893 年就预言:‘The great thought in physical education is not the education of the physical nature, but the relation of physical training to complete education。' 指出体育当中最伟大的思想不是对身体本身的培养而 是通过身体对整个人的教育。[6]蔡元培先生曾说: “西 洋有一句成语, 叫做健全的精神, 宿于健全的身体, 足 作学生的精神, 并不是只在奢赛跑跳 ......” [7]教育家 张伯苓提出“教育里没有了体育, 教育就不完全”, 并认 为“最要者学校体育不仅在技术之专长, 尤重在体德之 兼进, 体与育并重, 庶不致发生流弊, 故体育道德, 及 运动精神, 尤三致意焉”。[8]毛泽东更是提出“体育之效, 至于强筋骨, 因而增知识, 因而调感情, 因而强意志。 筋骨者, 吾人之身; 知识, 感情, 意志者, 吾人之心。 身心皆适, 是谓俱泰。故夫体育非他, 养乎吾生、乐乎 吾心而已”。[9]经过先进体育思想的引领和体育工作者 教育实践的摸索, 体育从“身体的教育”向着“通过身体 的教育” 发展, 不只关注身体层面, 更注重通过体育来 实现人的整体发展、精神的振作、体德的兼进以及身心 的一统，从“身体的教育”到 “通过身体的教育”是体育 发展历程中在理论意义上的一次回归和飞跃。

\section{4. 一流大学建设视角的体育人文教育途径重构}

此文的撰写正是在全国抗击新冠状病毒肺炎的特 殊时期, 在此期间读《体育使教育有一种向上的精神

一钟南山院士谈改善中小学生体质》一文, 深有感触。 在钟南山院士看来, 体育让他不服输、有力争上游精神; 体育让他不怕输、不怕挫折、提高意志品质; 用时间就 见体育的不可轻忽, 不过体育是要发达学生的身体, 振 
应该像在运动场上那样, 分秒必争, 讲求效率; 协作精 神也是从体育方面得到的一种素质。钟南山院士认为 “体育使教育有一种向上的精神。体育给我的工作、学 习、生活带来的帮助远远超过了增进身体健康的范畴, 在体育上得到的东西运用在学习和工作中, 会受益无 穷”。[10]一流大学建设视角下的体育人文教育的核心, 就是让学生在体育运动实践中觉解体育精神并升华精 神品质, 进而对人的生命实践产生积极的影响和指导。

\section{1 以体育精神哺育人才的精神内核}

《统筹推进世界一流大学和一流学科建设总体方 案》提出 “坚持以学科为基础” 是一流大学和一流学科建 设的基本原则, 同时也明确了培养拔尖创新人才这一建 设任务, 方案对“拔尖创新人才”是出于“德”、“使命感”、 “责任心”、“创新精神”等内在素养来描述的。什么是“一 流人才”我们不敢妄加评论, 但创新型、应用型、复合 型优秀人才一定是具有 “一流”精神内核的。体育不只是 为了身体健康, 更能培养很多好的品质, 这些品质会对 从事其他领域的工作、科研和生活产生极大影响。

\subsection{1 坚持体育的人文教育价值与功利性价值有机结 合}

“在重视人文精神、重视体育的人文价值的同时， 要避免把它与功利价值对立起来。现实中“重利轻义”的 现象是片面的, 但因此而“重义轻利”, 甚至“以义抑利” 也是不可取的”。[11]单一的搞“体质论”、“技术论”、“体 能论”、“竞技论”固然是不可取的，但体育人文教育绝 非是将体质、体能、技术、竞技于不顾而盲目追求“精 神至上”, 那样的话将会使体育人文教育失去它的生动 性和深刻性。

体质、体能不但要搞, 还要搞得更好。在注重科学 锻炼的前提下考虑学生的情感和需求, 适当加入趣味性 的练习手段, 在得到学生认知和情感上的认同后才能激 发参与的主动性, 这样的体能、体质训练才能成为引导 坚㓞、刻苦等品质的源泉。

运动技能不但要教, 还要更便于学生掌握。体育是 以身体活动为手段的教育方式, 体育人文教育更要坚定 身体活动这一载体, 学生们掌握了基本运动技能才能更 好的体验运动乐趣, 有了乐趣才能主动参与, 积极主动 的接受了载体, 寓教于乐才能得以实现。

学校课余体育竞赛不但要大力开展, 还要让更多的 人参与其中。课余体育竞赛是体育人文教育的重要环节, 也是开展体育人文教育的主要手段。很多体育精神都需 要在竞赛中体悟, 经过比赛的历练才能对“我要赢”、“输 得起”、“拼一下”、“团队配合”等精神体会的更深刻。学 校课余体育竞赛在级别上小到教学班的教学比赛, 大到 全国大学生体育锦标赛甚至更高级别, 形成全员参与为 基础、精英锦标为突破的金字塔结构; 组织形式灵活、 竞赛项目丰富的同时, 公平公正的竞赛环境是培养学生 规则意识和自律的前提; 搞比赛不能只注重结果, 冠军
毕竟只有一个, 组织者须重视竞赛过程对参与者拼搏进 取、精益求精、迎难而上、团结协作等品质的激发。

\section{1 .2 遵循体育人文教育目标导向的多元性}

运动项目特点的差异性、体育文化的多样性、学生 发展的个性化决定了体育人文教育目标导向的多元性。

不同项目具有不同的运动特点，不同的选项课在开 展体育人文教育时的主要目标也有区别。如健身跑、体 适能、健美运动等体能类项目更适用于培养学生克服困 难的精神和磨练刻苦坚韧的意志; 足球、篮球、排球等 团体竞技类的项目更侧重于培养团队精神、规则意识和 沟通能力等; 形体舞蹈类项目更多的是对审美的追求; 太极、导引养生功等比较静的项目更有利于培养学生求 精与谦和; 短兵、散打、跆拳道等格斗技击类项目更强 调培养学生的勇敢精神和应变能力。

不同的项目承载不同的体育文化，用于教学时也要 在人文导向上有所侧重。例如, 网球运动作为一项“绅 士运动”，可以在培养基本体育人文素养和精神的基础 上更侧重于诚信、尊重和为同伴考虑; 射艺承载了丰富 的儒家文化, 可以在教学中注重它的养德、正己、绎志、 诸己等作用; 传统武术类项目是优秀民族传统文化的载 体, 可以侧重于对自强、精诚、崇德等精神的熏染。

因材施教是教育的基本原则, 全面发展也并非面面 俱到、整齐划一，体育人文教育要注重个性化发展。如 太极拳教学中同样是做一个白鹤亮翅动作，一伸手就是 大开大合、动作夸张的学生多数是有自信而缺乏内玫, 而缩手缩脚、动作过于拘谨的学生可能比较细致但缺乏 自信和果断, 这就为我们的差异化的引导提供了参照和 方向。体育育人的优势之一就在于它能够在“动”的过程 中反映学生的内在特点, 优秀的体育教师能够根据学生 的个体差异选择相应的引导方式和教辅行为, 并以“动” 的形式作用于不同个体的身心, 促进学生在原有基础上 实现个性化的发展。

\section{1 .3 保留体育人文教育方式的内隐性}

体育人文教育的内容和方式具有内隐性特点, 它是 通过身体活动这种载体将人文教育隐含在教学过程中 并潜移默化的发挥着作用。广大的学校体育工作者其实 一直都在有意或无意的实施着体育人文教育活动, 我们 的学生也或多或少的通过体育在道德修养、思想品质、 体育精神、良好人格等方面得到了受益。体育人文教育, 多数情况下是在受教育者无意识的心理活动和教育者 有意识的教学过程中实施的。内隐性要求体育教师多一 些目标导向上的有意识, 教育教学方法上最大程度的保 留体育的“原汁原味”，避免形成“说教式”的教育方式， 不然容易使受教育者产生抵触心理和反感情绪, 那样就 失去了体育人文教育的深刻性和实践性。 


\section{项目基金}

本文为吉林省高教科研课题《一流大学建设视角下 的地方工科院校体育人文教育研究》的阶段性成果之一。

\section{REFERENCES}

[1] State Council of China. (2015) Overall plan for promoting the construction of world-class universities and disciplines. http://www.moe.gov.cn/jyb_xxgk/moe_1777/moe_17 78/201511/t20151105_217823.html.

[2] Zhang, Ch.T. (2001) University Education of Humanities and Emancipation of Man. Journal of Higher Education, 32(02): 1-7.

[3] Lin, S.T. (1984) Archery and Riding in school education in the Western Zhou Dynasty. China Sport Science, (02):7-11.

[4] Dai, S. (2007) She Yi. The Book of Rites. Blue Sky press, Beijing. pp. 371-378.

[5] Fan, J. (2011) Physical Activity as the Origin of Paideia-The Meaning of Ancient Greek Physical Activity to Paideia. Doctor, Hunan Normal University, Changsha, pp. 7-9.

[6] Wei, L.Y., Yang, W., Han, F. (2011) Queries about that "physical education" is not "bodily education"-Also a discussion about the crux of the study of the nature of physical education in China. European Journal of Operational Research Journal of Physical Education, 18(03): 1-6.

[7] Cai, Y.P. (1980) Selected works of Cai Yuanpei's education. People's Education Press, Beijing.

[8] Zhang, B.L. (2006) Review of 40 years of Nankai school. Basic Education, (5):30-31.

[9] Mao, Z.D. (1917) Research on Sports. LA JEUNESSE , 03(02).

[10] Liang, W.G., Liu, Q. (2007) Physical education is an upward spirit of Education-- Academician Zhong Nanshan talks about improving students' physique. People's Education, (05):2-4.

[11] Yang, W.X. (2004) Sports principle. Higher Education Press, Beijing. pp.57. 改革和发展的方向。体育在一流大学建设中支撑着人才 培养、文化传承等大学职能, “学校好不好, 还看体育 佬”, 体育教师任重而道远。 